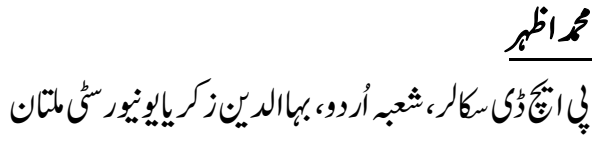

$$
\begin{aligned}
& \text { واكرماردمول }
\end{aligned}
$$

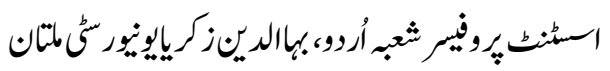

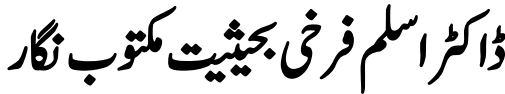

Muhammad Azhar

Ph.D Scholar Department of Urdu, BZU, Multan.

Dr. Hamad Rasool

Assistant professor Department of Urdu BZU, Multan.

\title{
Letter Writing of Dr. Aslam's Farkhi
}

In Urdu literature, Dr. Aslam Farkhi is a unique writer due to his creative aspects. He is a sketcher, researcher, critic, editor, columnist, playwright, novelist and letter writer. As a sketcher, he penned the culture and values associated with the personalities he wrote about. As a researcher and critic, he took Urdu research and criticism out of the realm of traditional research and criticism and introduced it to scientific and modern scientific insights. Apart from drama and fiction, as a children's writer and columnist, he enriched all these genres with his enlightenment and knowledge.

Keywords: Letter Writing, Vrdu Literature, traditional research, culture, Scientific insight, enlightenment and Knowledge.

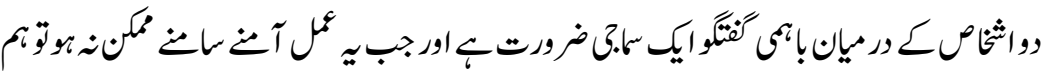

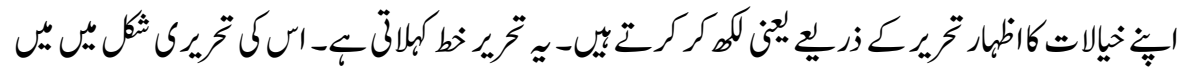

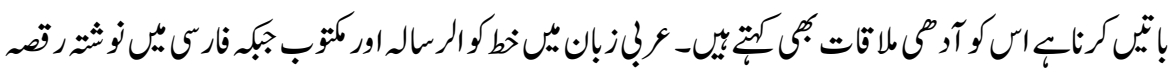

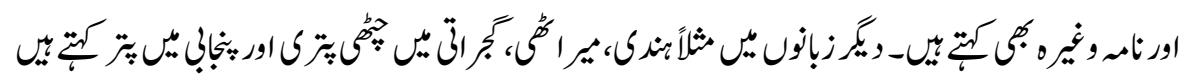

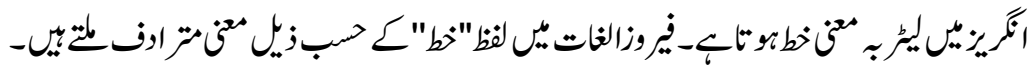

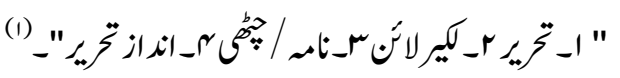

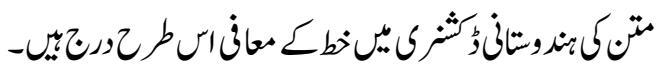


"Written communication sent to person by post" An art of light literature ${ }^{(r) "}$

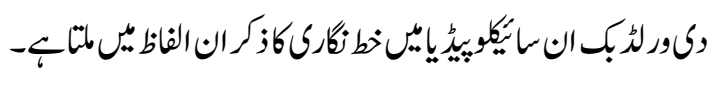

"Letter written is a way of commoniating a message in written words " $(r)$

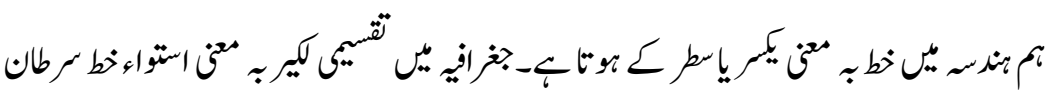

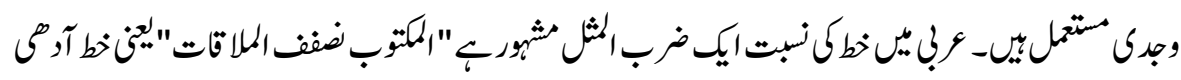

$$
\begin{aligned}
& \text { كات إن }
\end{aligned}
$$

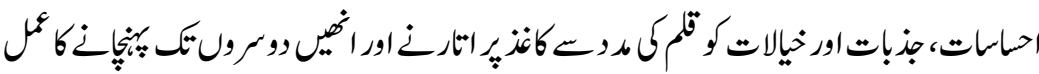

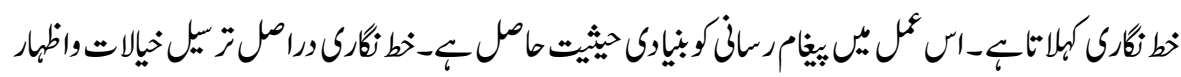

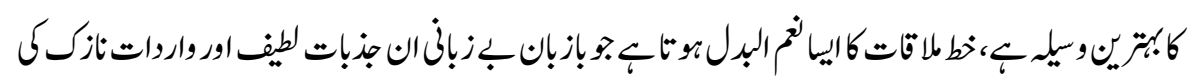

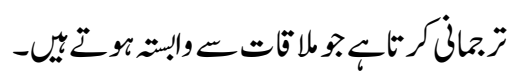

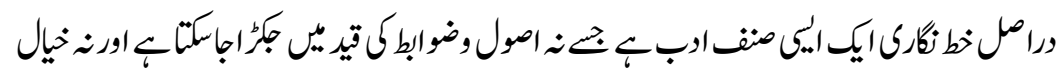

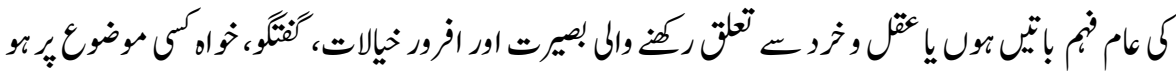

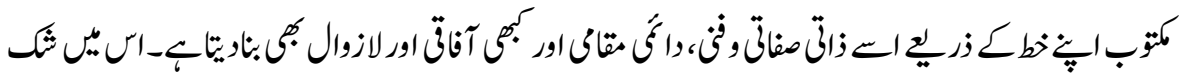

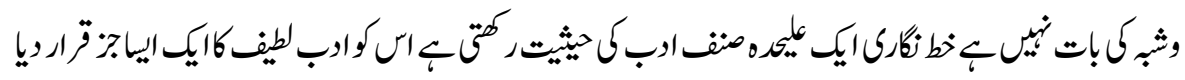

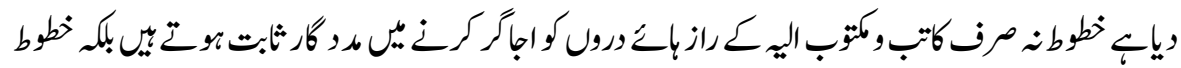

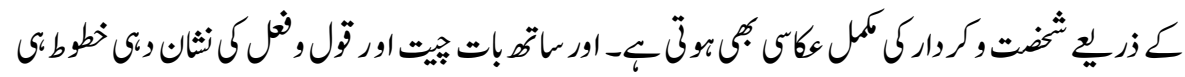

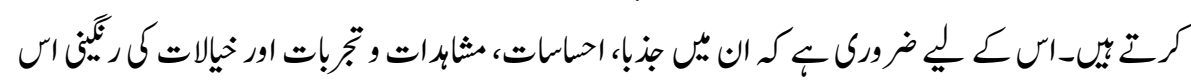

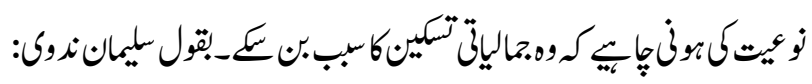

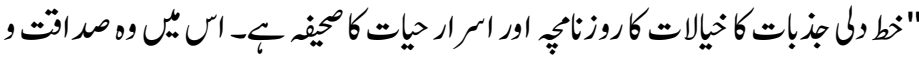

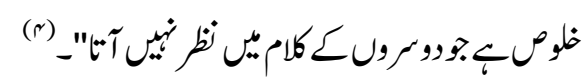




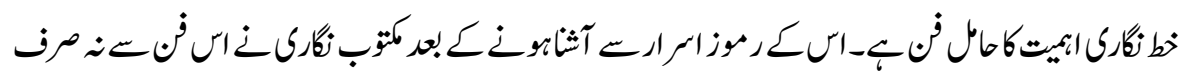

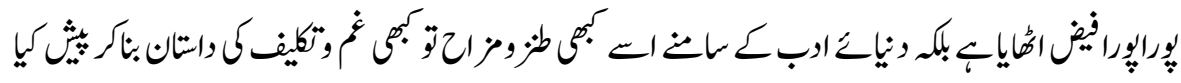

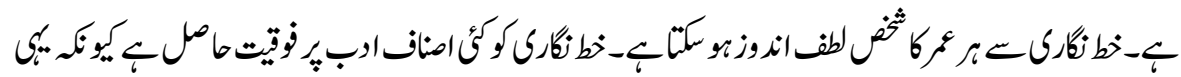

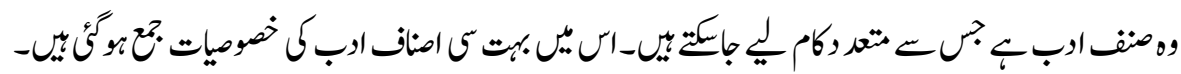

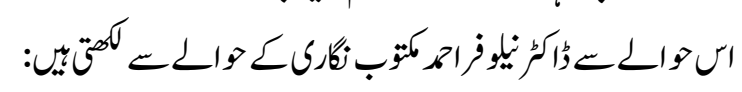

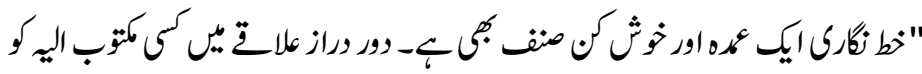

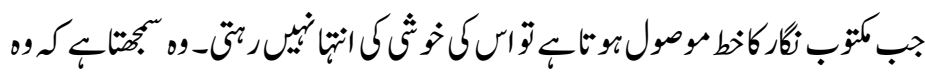

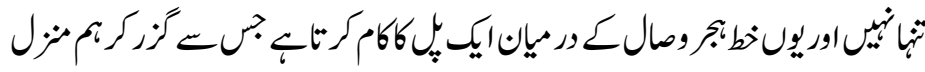

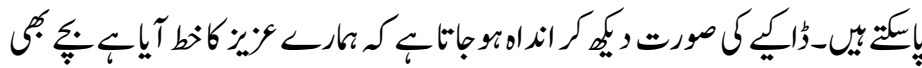

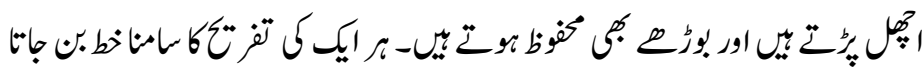

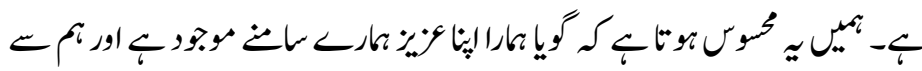
(ه) -4

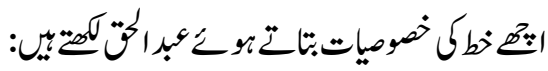

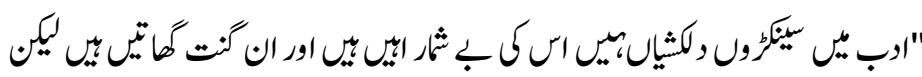

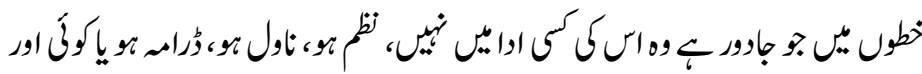

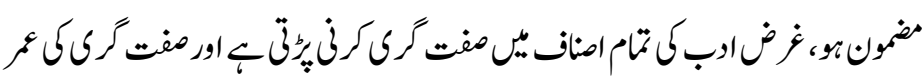

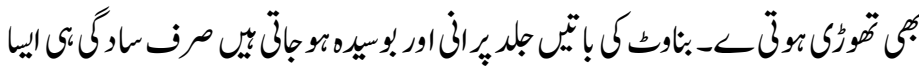

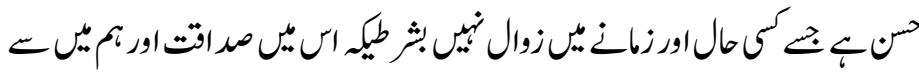

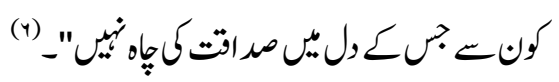

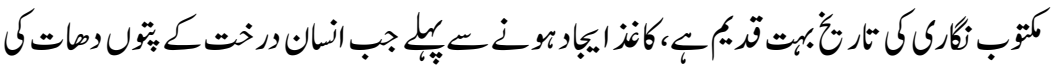

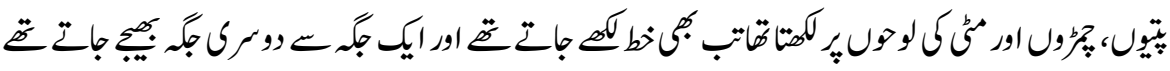

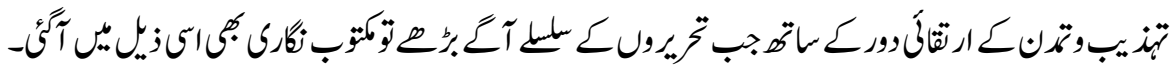




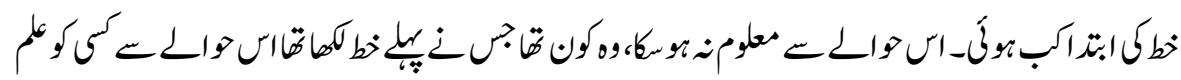

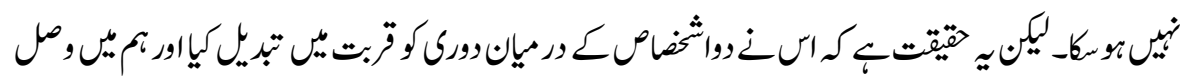

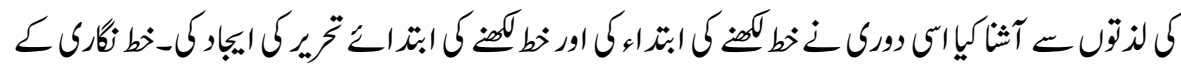

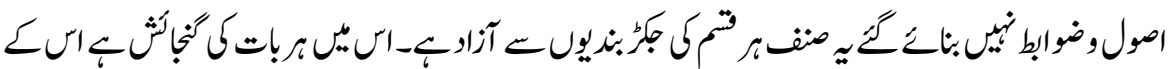

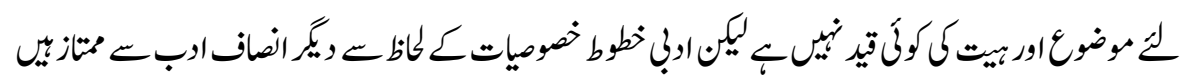

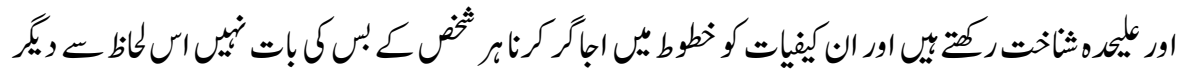

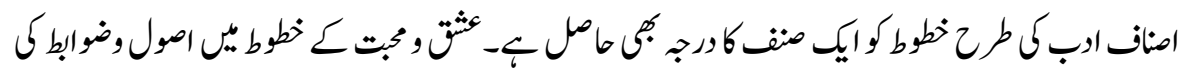

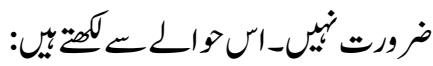

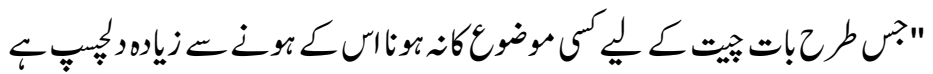

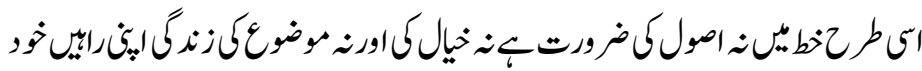

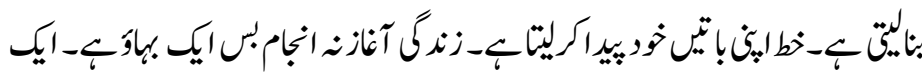

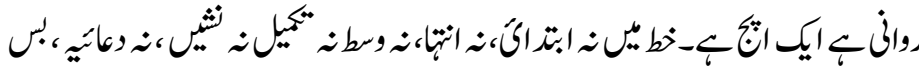

$$
\text { (८) }
$$

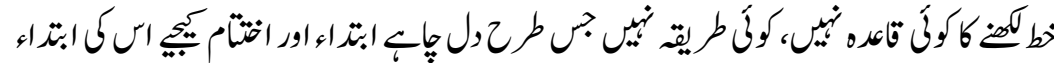

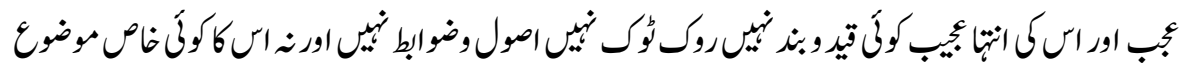

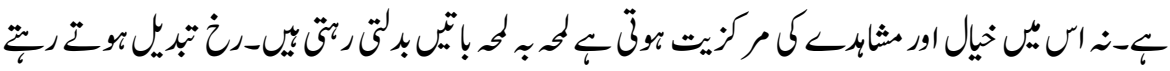

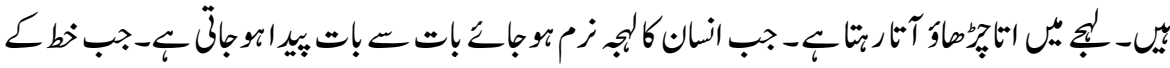

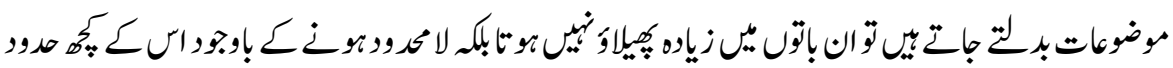

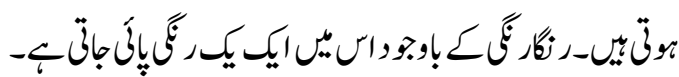

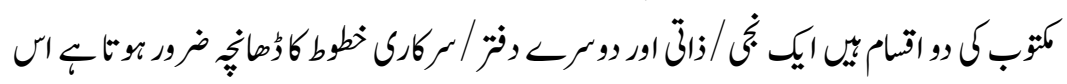

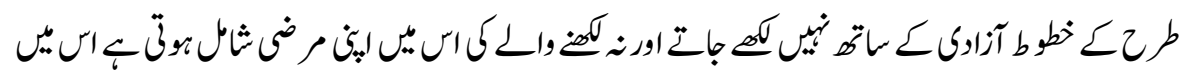

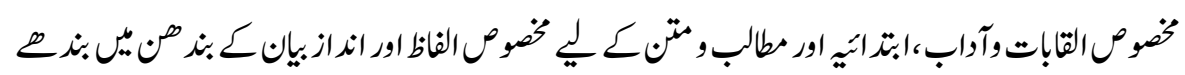

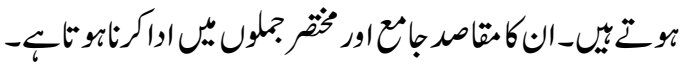




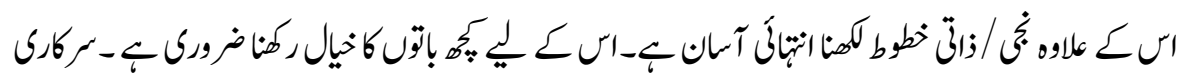

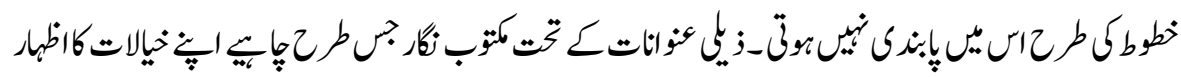

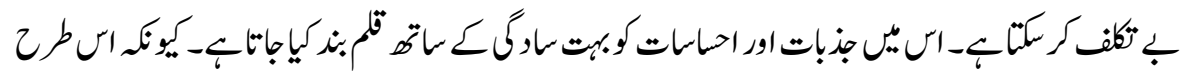

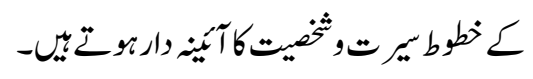

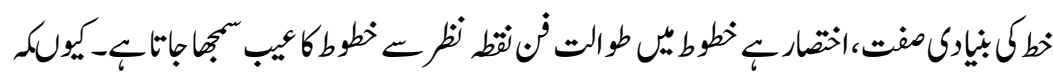

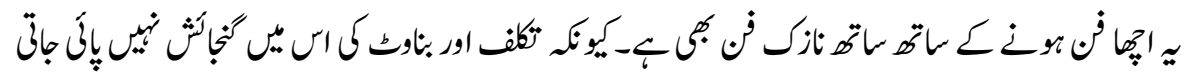

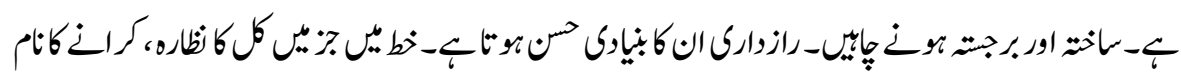

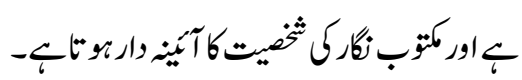

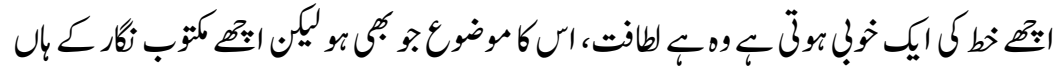

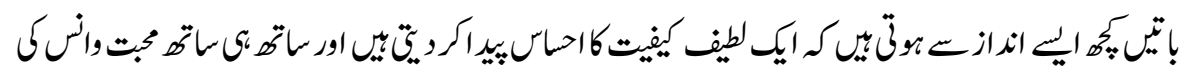

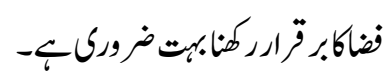

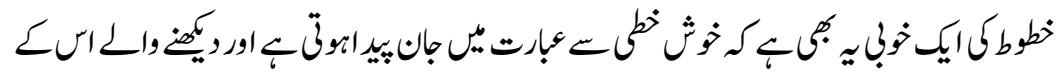

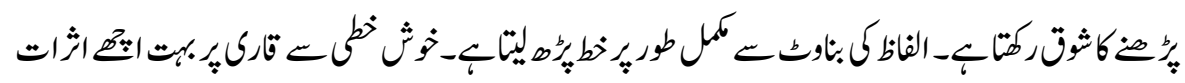

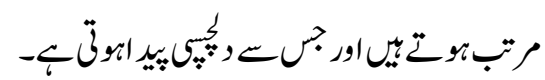

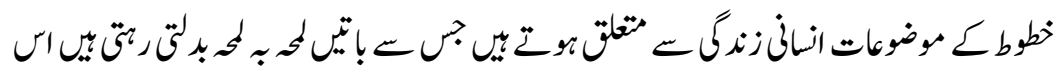

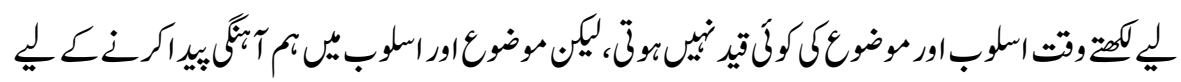

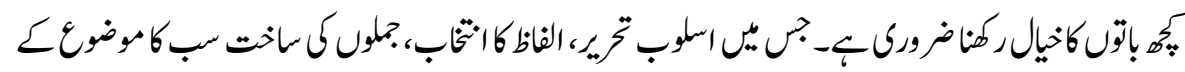

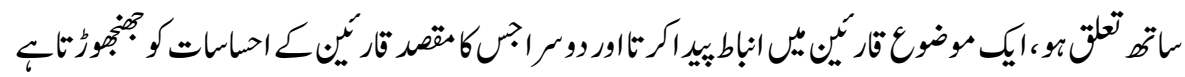

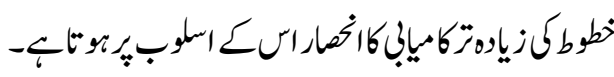

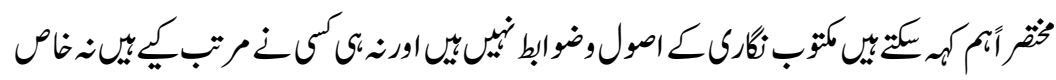

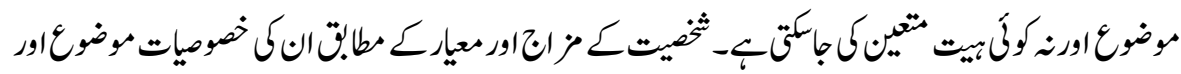

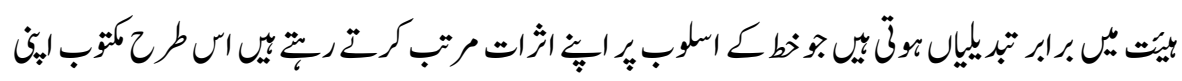

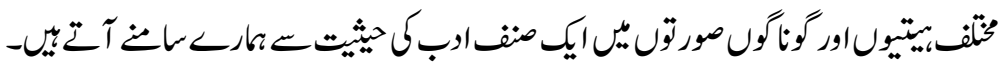




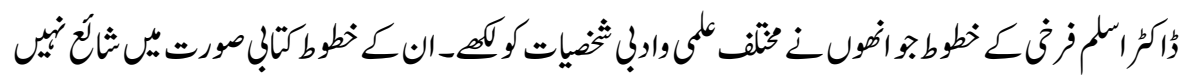

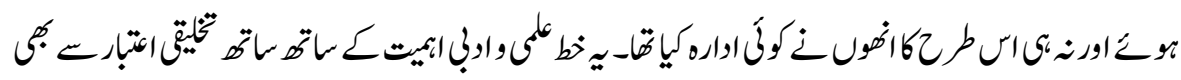

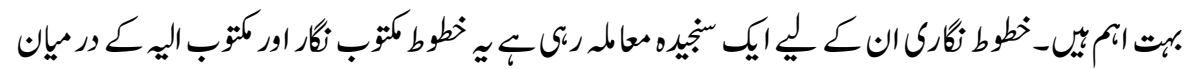

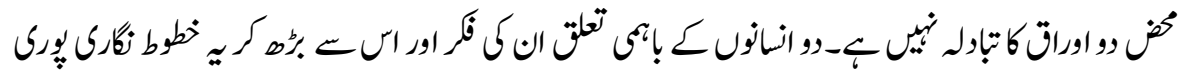

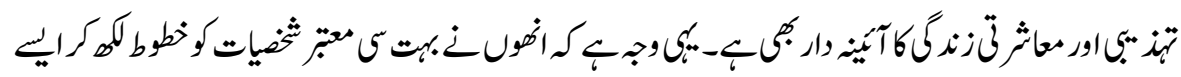

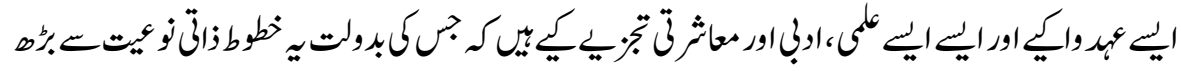

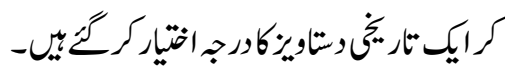

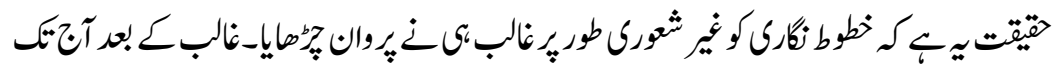

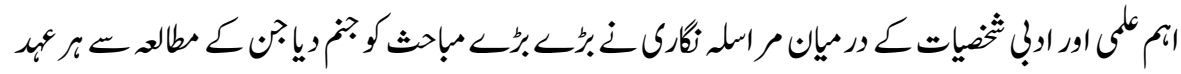

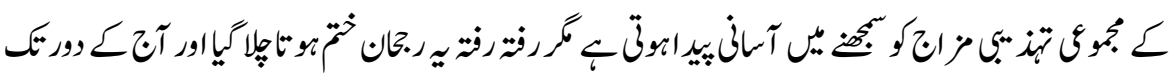

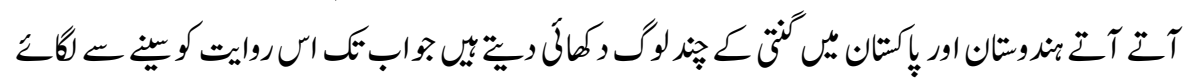

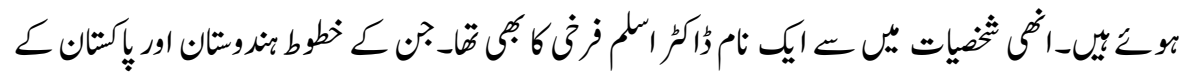

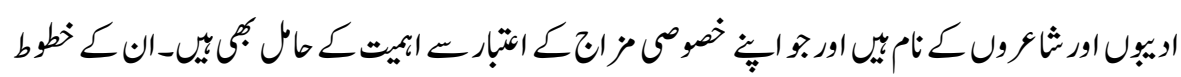

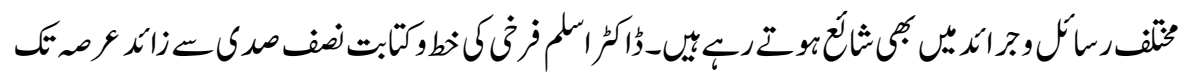

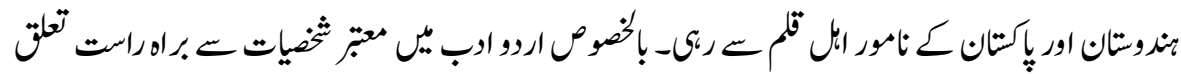

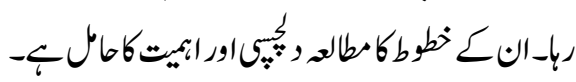

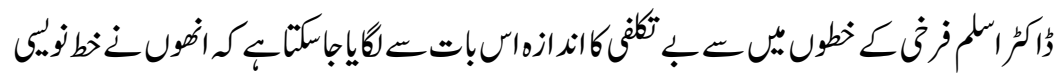

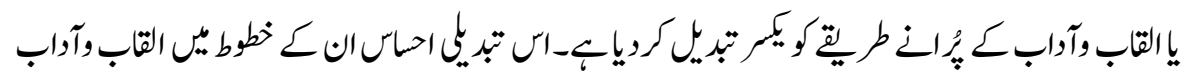

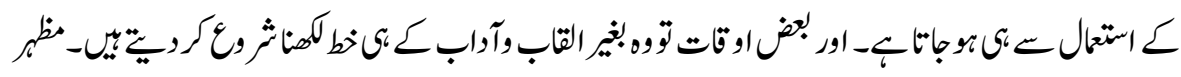

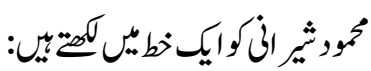

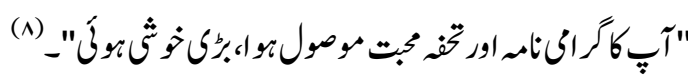

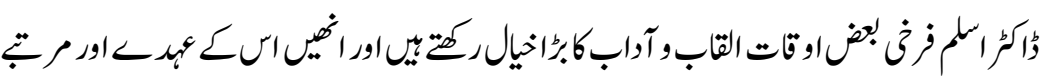

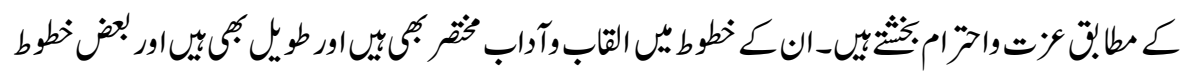




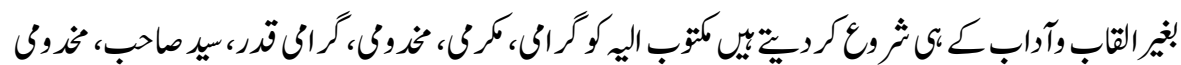

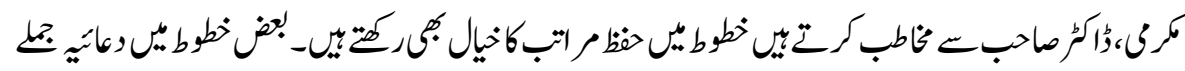

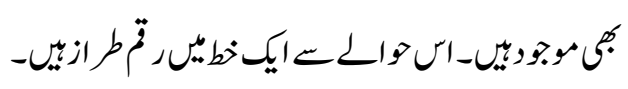

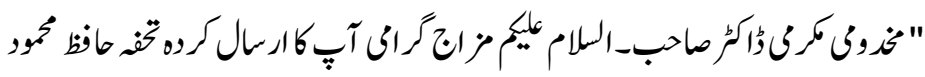

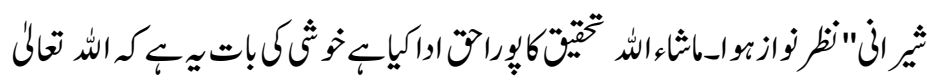

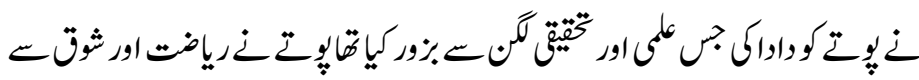

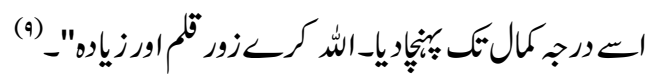

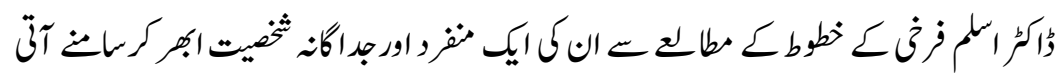

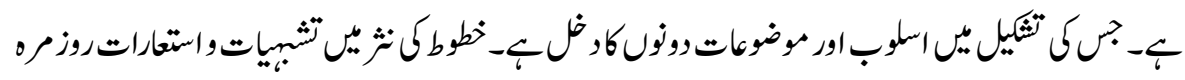

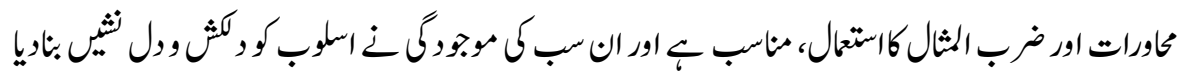

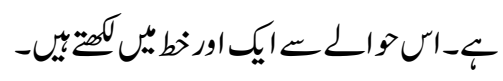

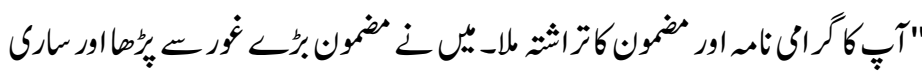

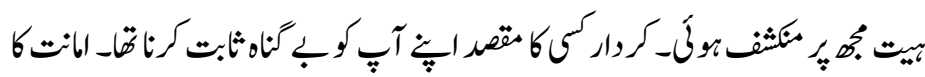

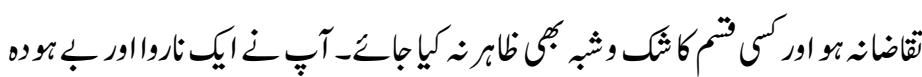

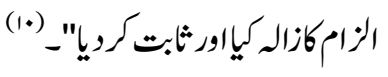

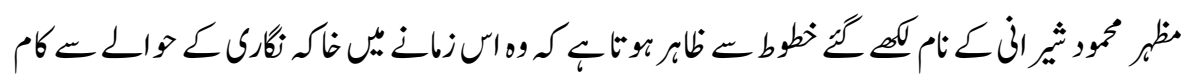

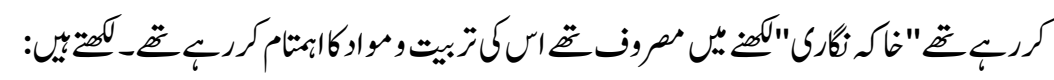

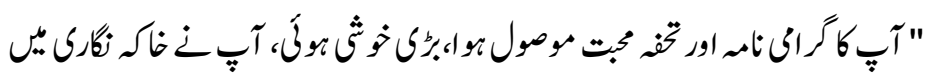

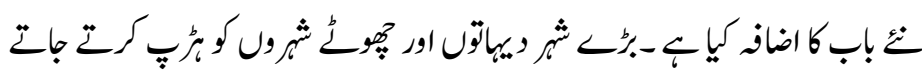
(11)

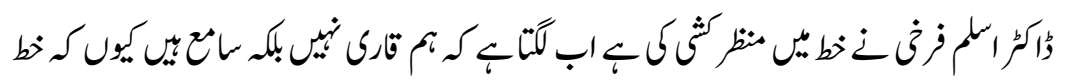

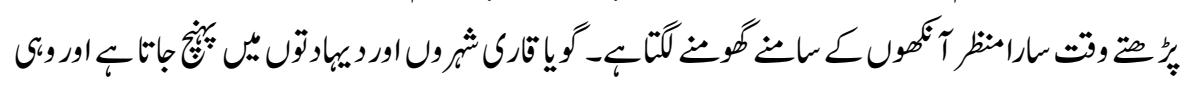

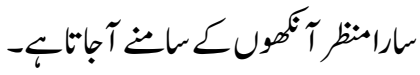




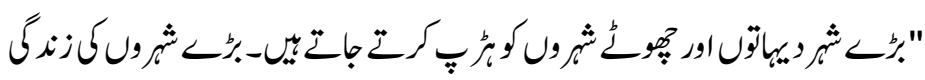

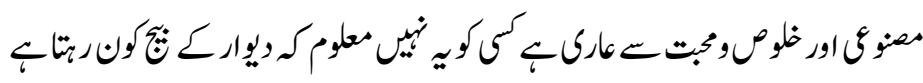

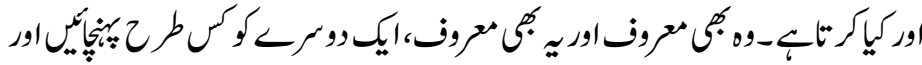

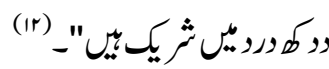

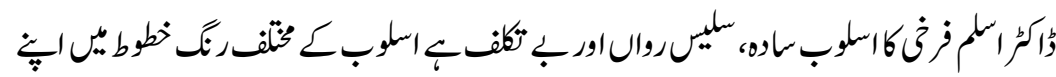

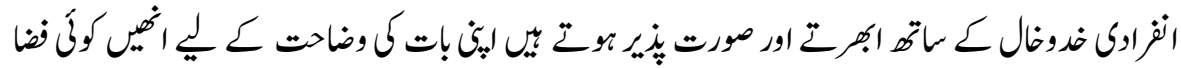

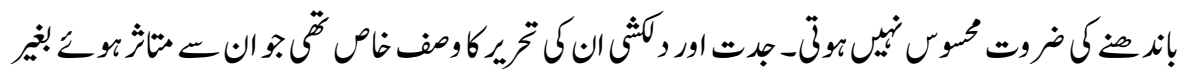

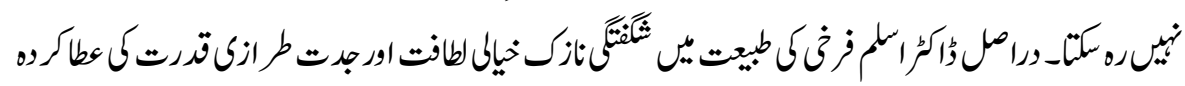
:

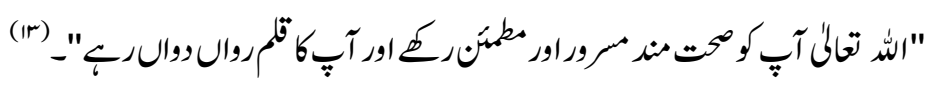

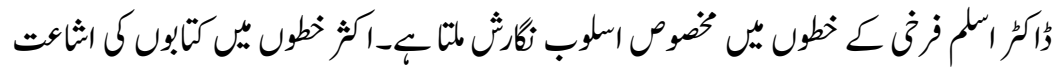

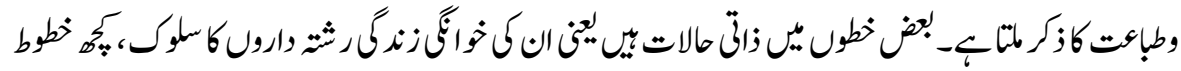

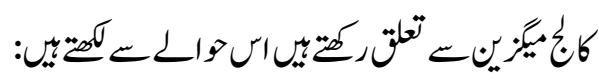

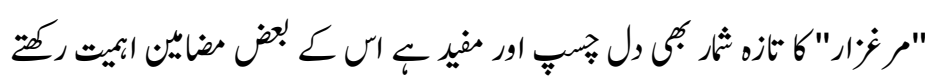

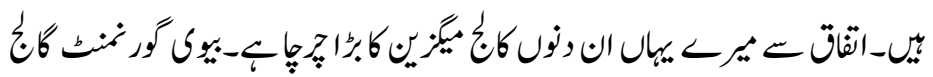
.

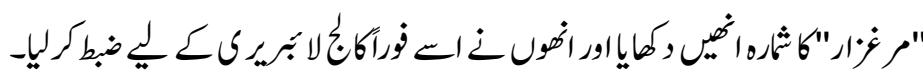

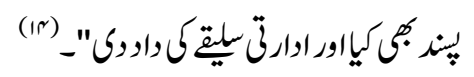

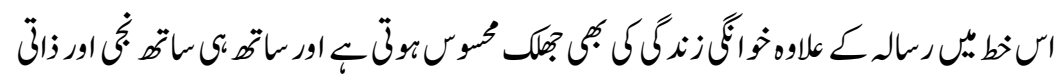

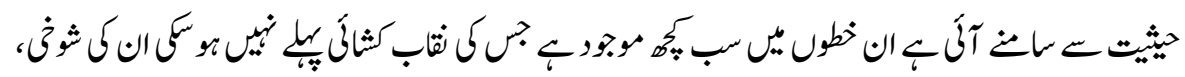

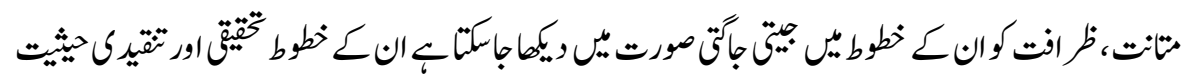


ISSN (Print): 2709-9636 | ISSN(Online) : 2709-9644 | ISSN-L : 2709-9636

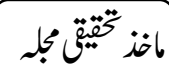

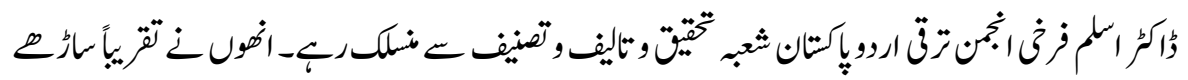

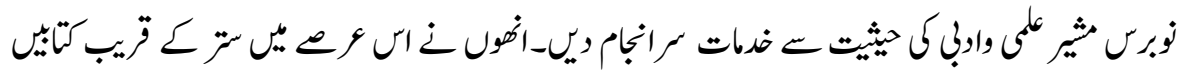

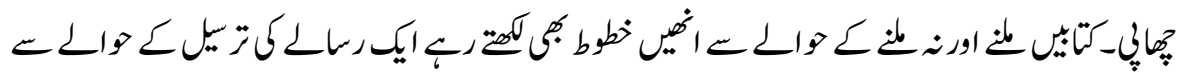

:

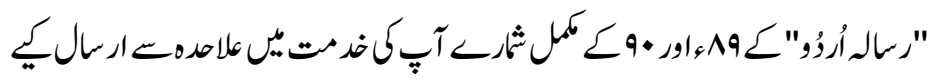

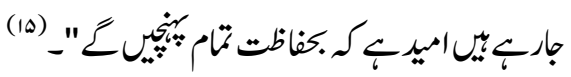

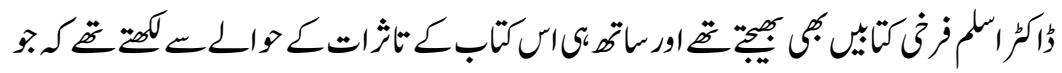

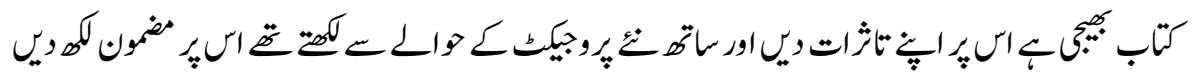

اسنا

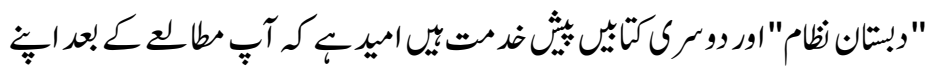

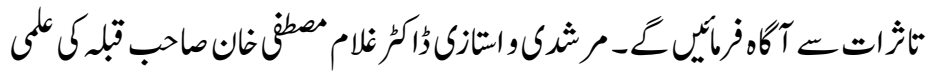

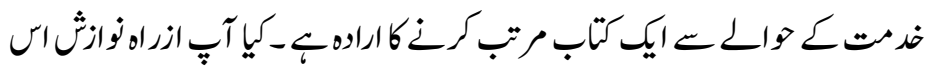

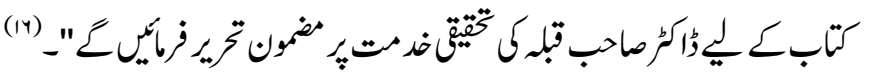

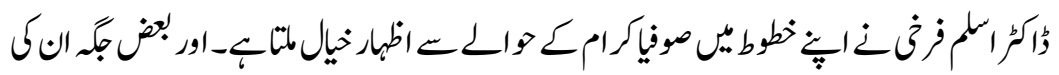

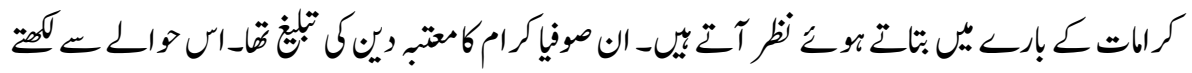

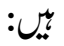

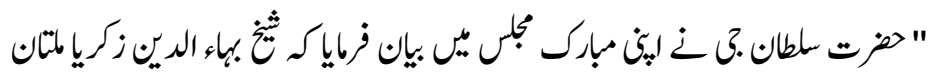

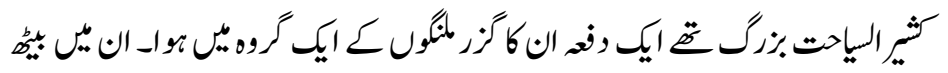

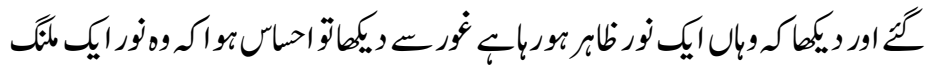

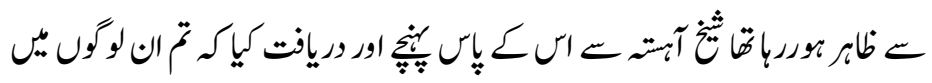

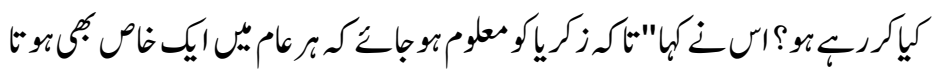

(1) $-" \leftarrow$

ryy 


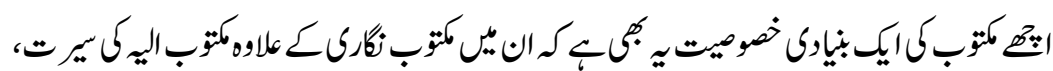

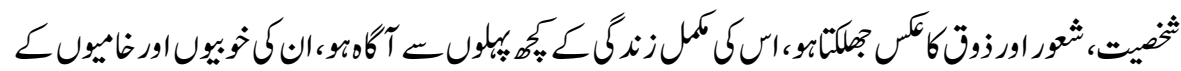

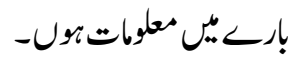

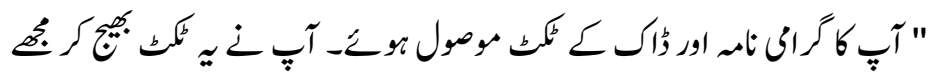

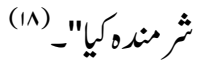

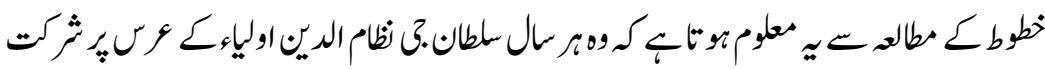

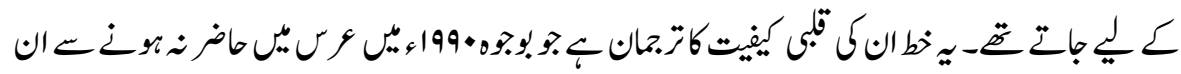

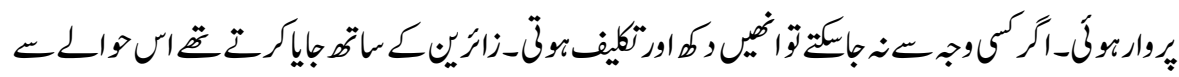
كلئين:

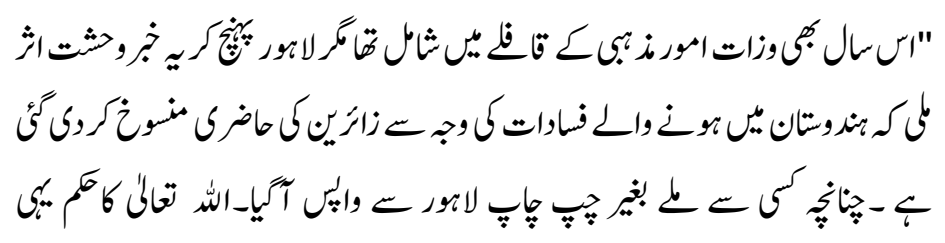
(19) $-" 6$

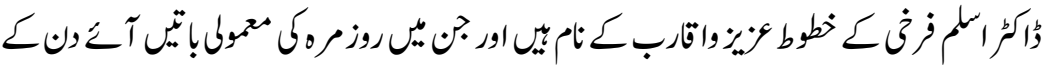

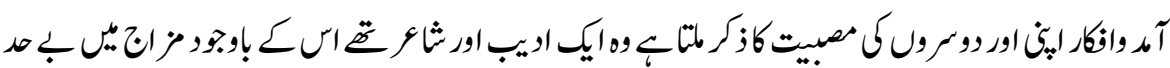

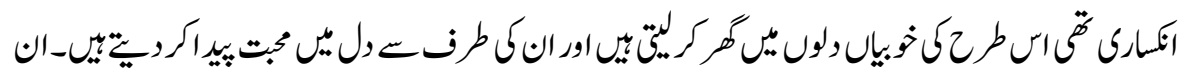

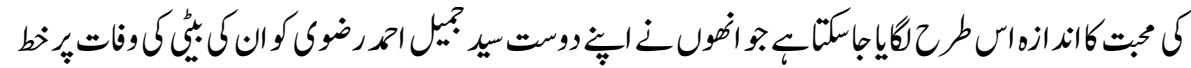
:

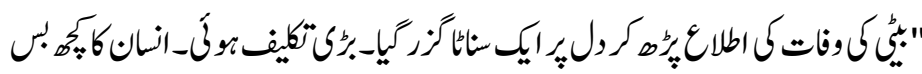

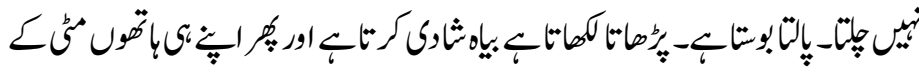

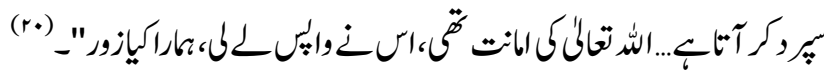

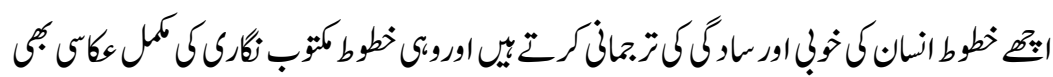

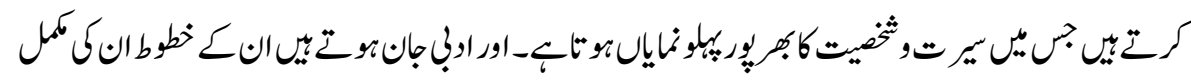




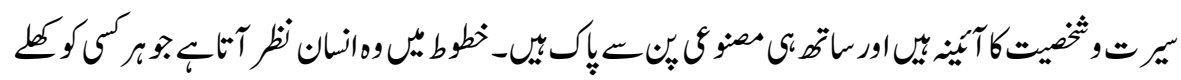

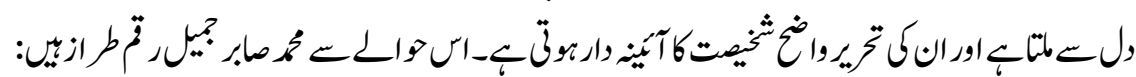

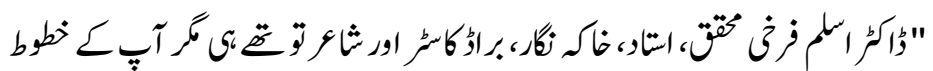

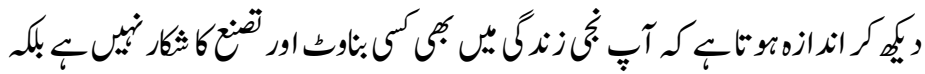

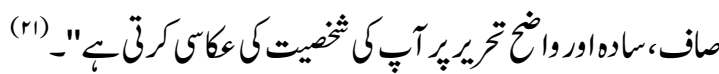

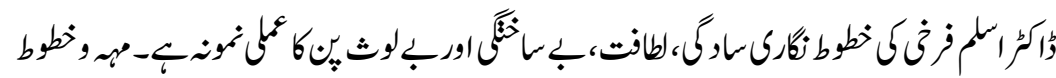

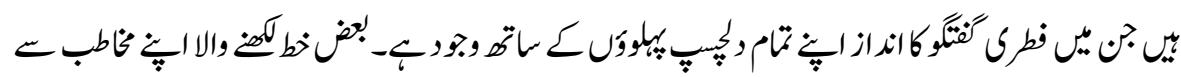

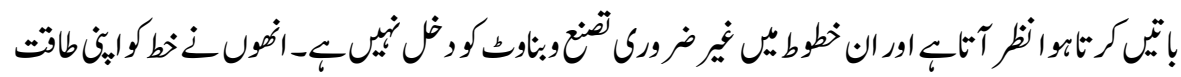

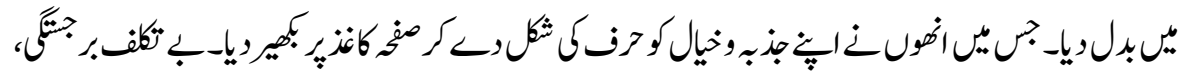

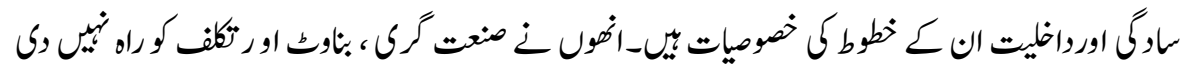

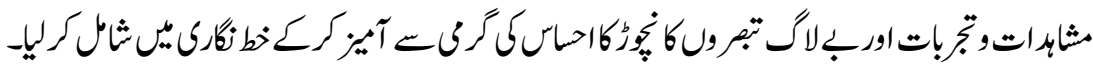

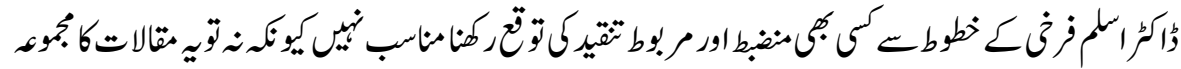

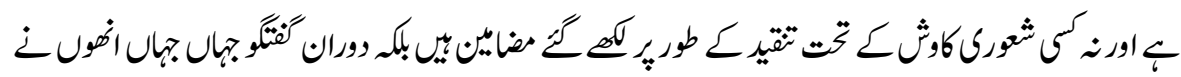

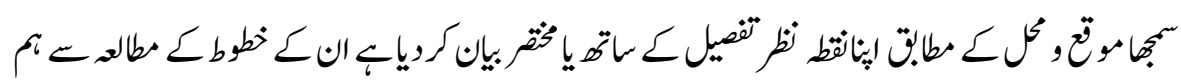

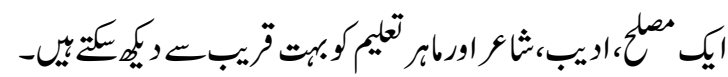
والرجات

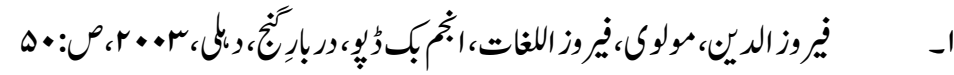

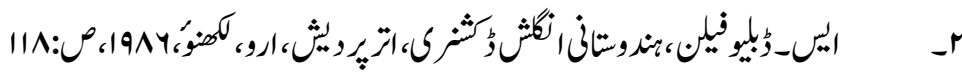

The world book of encyclopedia, wordin seoh, feitzer company, $\boldsymbol{-}^{\mu}$

London, 1992,P:186

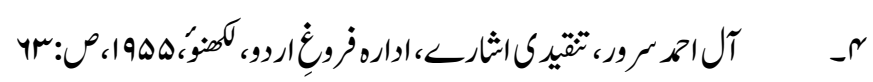

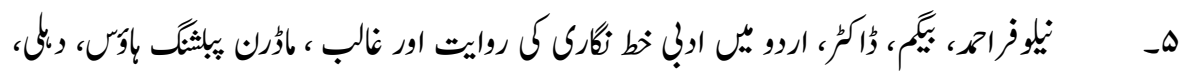

$$
\text { ra:e.r... }
$$




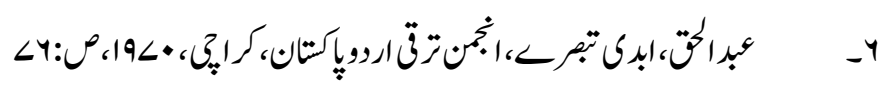

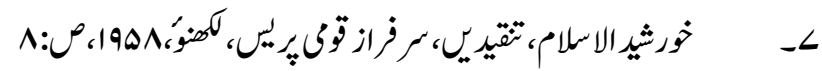

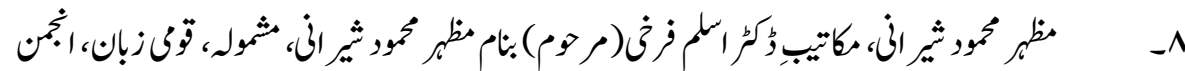

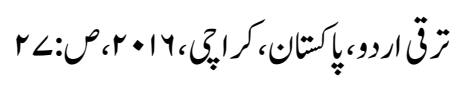

$$
\begin{aligned}
& \text { 9- } \\
& \text { •ا- }
\end{aligned}
$$

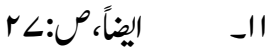

$$
\begin{aligned}
& \text { r r اليضأ، } \\
& \text { r } \\
& \text { ما- }
\end{aligned}
$$

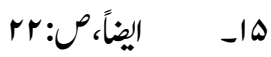

$$
\begin{aligned}
& \text { 14 إ- اليضاً، }
\end{aligned}
$$

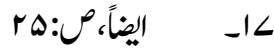

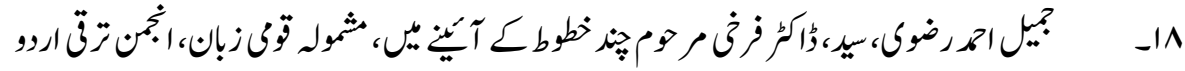

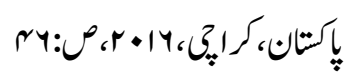

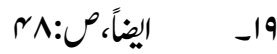$$
\text { r r r r r }
$$

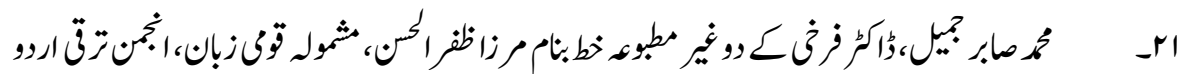

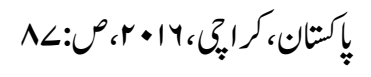

